\title{
Evaluating the Competition of Marine Tourism Industry Among Major Countries in Southeast Asia Using AHP Method
}

\author{
Hoang-Nam Truong, Woon-Jae Jang* \\ Maritime Transportation System Department, Mokpo National Maritime University, Mokpo, Korea \\ Email address: \\ hoangnam.mmu@gmail.com (Hoang-Nam Truong), jwj98@mmu.ac.kr (Woon-Jae Jang) \\ ${ }^{*}$ Corresponding author
}

\section{To cite this article:}

Hoang-Nam Truong, Woon-Jae Jang. Evaluating the Competition of Marine Tourism Industry Among Major Countries in Southeast Asia Using AHP Method. American Journal of Environmental and Resource Economics. Vol. 4, No. 3, 2019, pp. 104-109. doi: 10.11648/j.ajere.20190403.13

Received: May 24, 2019; Accepted: July 16, 2019; Published: August 5, 2019

\begin{abstract}
In recent years, tourism, especially in terms of marine tourism, has played an important role in the economic development of every country. Profits from tourism activities contribute a significant portion to their total annual incomes. Many countries have put great efforts into developing their marine tourism industries to attract tourists from all over the world. This has created fierce competition among countries which have similar geographic and natural conditions in the same region. In this study, the importance of factors that make a competitive marine tourism industry of major countries in Southeast Asia such as Vietnam, Thailand, Singapore and Malaysia were identified and evaluated by using AHP (Analytic Hierarchy Process). Questionnaires were given to candidates who are working in Southeast Asia or having experiences in traveling to the area to determine the weight of these factors and the preferred country to travel. The results show that Singapore was the most preferred tourism country in Southeast Asia and Quality was the most important factor to be concerned when the tourists consider traveling to the area. Moreover, the strengths and weaknesses of each country have been indicated and provided as useful information for tourists who are planning to visit the Southeast Asia region.
\end{abstract}

Keywords: Multi Criteria Decision Making, AHP, Marine Tourism Industry, Fierce Competition, Southeast Asian Countries

\section{Introduction}

Southeast Asia is a sub-region of Asia. It is located in the south of China and to the east of India. Much of Southeast Asia is islands in the Indian Ocean and the Pacific Ocean. The climate in the area is mainly tropical-hot and humid all year round with plentiful rainfall. Temperatures are generally warm, although it is cooler in highland areas. Many sea and jungle products are unique to the region. The countries in the area are gifted with beautiful landscapes, long and attractive beaches and a variety of rare materials used to make many delicious foods. Moreover, the improvement in technologies and infrastructures in recent years has contributed considerably to the promotion of the country's image to all travelers around the world. Vietnam, Thailand, and Malaysia have similar climatic and geographical conditions. However, referring to tourism in Southeast Asia, it is impossible not to mention Singapore, a country with a small area and population when compared with the three above countries but has advantages of infrastructure as well as science and technology developments. For a long time, Singapore, Malaysia, and Thailand have been the top three countries and their tourism industries are different from the rest of Southeast Asia. Meanwhile, Vietnam has been named as the most improved country with the highest tourism growth rate in Southeast Asia and the 4 places in the world in 2017 [1], only behind Japan, Azerbaijan, and Tajikistan. Also, Vietnam has been considered an interesting and potential tourism market in the coming years. Each country has its strengths and weaknesses to attract tourists. This has created fierce competition among these countries nowadays.

In this study, the level of tourism competitiveness among four countries was evaluated by using the AHP method. The result from this study provides useful information for 
travelers who are planning to visit the Southeast Asian region. As a further matter, a comparative analysis between the findings from this research and the statistics from UNTWO (United Nations World Tourism Organization) and WTTC (World Travel and Tourism Council) was also carried out to confirm the reliability and accuracy of the AHP model.

\section{Research Background}

\subsection{Marine Tourism Status of the 4 Countries in 2017}

According to the World Economic Forum, most of the Southeast Asian countries are ranked above the 50th position in the Travel and Travel Competitiveness Index 2017 ranking [1]. The advantages of the countries are their natural resources and competitive prices. However, there is still a large infrastructure and technology gap that remains between the most advanced in the area, especially Singapore and Malaysia, and to a less extent Thailand, versus the rest.

In 2017, Vietnam tourism welcomed more than 12.9 million international visitors, up by 30 percent compared with 2016. The direct contribution to the country's GDP reached 12.8 billion USD [2], up by 40 percent compared to the same period in 2016 [3]. In addition, the industry also supported more than 2.4 million jobs along with the investment for the industry was at 5.1 billion USD. Meanwhile, Singapore attracted more than 17 million international visitors, up by 6.2 percent compared with 2016 and more than 3 times of the country's total population. The direct contribution to the country's GDP reached 13 billion USD, up by 3 percent compared to the same period in 2016. Besides, the industry also supported more than 169 thousand jobs along with the investment for the industry was at 14.5 billion USD. Malaysia received more than 25.7 million international visitors, down by 4 percent compared with 2016 . The direct contribution to the country's GDP reached 15.2 billion USD, up by 8 percent compared to the same period in 2016. Also, the industry also supported more than 669.8 thousand jobs along with the investment for the industry was at 5.3 billion USD. In 2017 , Thailand invited more than 35 million international visitors, up by 7.4 percent compared with 2016. The direct contribution to the country's GDP reached 42.2 billion USD, up by 14.9 percent compared to the same period in 2016 . The industry also supported more than 2.3 million jobs along with the investment for the industry was at 7.7 billion USD.

\subsection{Literature Review}

There are several criteria that impact the selection of travel destinations. Some previous studies have used decision-making methods in evaluating the importance of factors to select the tourism destinations which are mentioned in the following part of this paper. Murphy (1999) [4] used variables like safety and cost to measure tourists' perception in Australia. Lai and Graefe (2000) [5] used factors like possibility of entry, attractions, infrastructure and safety for developing possible destination choice criteria while studying Taiwanese overseas travelers. In Kaushik paper (2010) [6], the key elements related to the choice of the destinations based on Hindu people habit were infrastructure, attractions, tour guides services, traditional festivals, local cuisines, and environmental conditions. Nekooee, Karami, and Fakhari (2011) [7] assessed the prioritization of urban tourist attractions based on AHP method in Iran. They indicated that the key criteria were cost, infrastructure, and local cuisines. B. Centisoz and S. Artuger (2014) [8] used the data obtained from 397 tourists to determine the reasons why foreign tourists traveling to Istanbul. Factor analysis, reliability analysis, t-test, and variance analysis were deployed to analyze the data. The analyzed results indicated that tour guides quality, attractions, infrastructures quality were the most important factors. Javid Seyidov and Roma Adomaitiene (2016) [9] analyzed factors influencing decision-making of local tourists in choosing Azerbaijan as a destination. They found that destination infrastructures, environmental conditions, tourism activities and cost are the most important attributes. Angelos Pantouvakis and Chritos Patsiouras (2016) [10] investigated the most important criteria that prompted tourists to visit a destination and the effect of tourists' nationality to their choice. The results of the paper made clear that the main factors for tourists' destination choice are possibility of entry, traditional attractions, security, environmental conditions, various activities, and cost. Kirti Singh Dahiya and Dharminder Kumar Batra (2016) [11] focused on "tourist decision making: exploring the destination choice criteria", for the popular heritage tourism circuit in India; the Golden triangle. The discovered factors that influenced tourist choice were local cuisines, convenience, tourism infrastructures, environmental conditions, and festivals. Maciej Debski and Wojciech Nasierowski (2017) [12] presented the ranking of the main criteria of destination choice based on a questionnaire study which used to get the opinion of young people from Canada, Poland, Trinidad and Tobago. The most important criteria found in their paper were cost, possibility of entry, variety of activities, traditional festivals, infrastructure quality, and environmental conditions. Luan Chen, Eric Ng, Shyn-Chang Huang and Wei-Ta Fang (2017) [13] applied the combination of Delphi and AHP method in their study. Delphi method that involved 17 experts providing confirmation about the evaluation criteria while AHP method indicated that infrastructures quality, tourism activities, and tour guides quality were the most important factors regarding to tourism destination selection. The important criteria chosen by the previous studies can be briefly summarized as in table 1 .

Table 1. Important criteria chosen in the previous studies.

\begin{tabular}{ll}
\hline Previous Researches & Mentioned Criteria \\
\hline Murphy (1999) & safety, cost \\
Lai and Graefe (2000) & possibility of entry, attractions, infrastructure, safety \\
Kaushik (2010) & Infrastructure, attractions, tour guides services, traditional festivals, local cuisines, \\
\hline
\end{tabular}




\begin{tabular}{|c|c|}
\hline Previous Researches & Mentioned Criteria \\
\hline & environmental conditions. \\
\hline Nekooee, Karami and Fakhari (2011) & cost, infrastructure, local cuisines \\
\hline B. Centisoz and S. Artuger (2014) & services quality, attractions, infrastructures quality \\
\hline J. Seyidov and R. Adomaitiene (2016) & cost, environmental conditions, infrastructure quality, tourism activities \\
\hline Angelos Pantouvakis and Chritos Patsiouras (2016) & $\begin{array}{l}\text { possibility of entry, traditional attractions, security, environmental conditions, various } \\
\text { activities, cost }\end{array}$ \\
\hline Kirti Singh Dahiya and Dharminder Kumar Batra (2016) & local cuisines, convenience, tourism infrastructures, environmental conditions and festivals \\
\hline M. Debski and W. Nasierowski (2017) & $\begin{array}{l}\text { cost, possibility of entry, various activities, traditional festivals, infrastructures quality, } \\
\text { environmental conditions. }\end{array}$ \\
\hline $\begin{array}{l}\text { Luan Chen, Eric Ng, Shyn-Chang Huang and Wei-Ta Fang } \\
\text { (2017) }\end{array}$ & infrastructures quality, tourism activities, tour guides quality \\
\hline
\end{tabular}

This paper refers to the above criteria and several factors studied by the mentioned authors. However, the research objects of this paper are four Southeast Asian countries, which are in a fierce tourism competition.

\subsection{Research Methodology}

Analytic Hierarchy Process (AHP) is one of the Multi Criteria Decision Making method that was developed by Prof. Thomas L. Saaty [14]. Because of its simplicity and ease of use, AHP is a popular method used by many decision-makers to choose the best solution among several alternatives across multiple criteria. This method can be proceeded through the following steps:

Step 1: Making Decision Hierarchy Structure for the study.

Step 2: Collecting data from experts or decision-makers corresponding to the hierarchical structure. The numerical scale from 1 to 9 to assess the relative importance between the two criteria is shown in table 2.

Table 2. Saaty comparison scale.

\begin{tabular}{ll}
\hline Verbal judgment & Numeric Value \\
\hline Extremely important & 9 \\
& 8 \\
Very Strongly important & 7 \\
Strongly more important & 6 \\
& 5 \\
Moderately more important & 4 \\
Equally important & 3 \\
\hline
\end{tabular}

Step 3: Making a comparison matrix based on collected data. Basing on the survey result, an important matrix is built. The matrix consists of $i$ row and $j$ column. If the value of $(i, j)$ is more than 1 , the criteria in the ith row is more important than criteria in the jth column. In contrast, the criteria in the jth column is more important than that in the ith row.

Step 4: Calculating Priority Vector

Step 5: Calculating Largest Eigen Value $(\lambda \max )$

Step 6: Calculating Consistency Index (CI) and Consistency Ratio (CR)

$$
\begin{gathered}
C I=\frac{\lambda \max -n}{(n-1)} \\
C R=\frac{C I}{R I}
\end{gathered}
$$

The value of RI is related to the dimension of the matrix and will be extracted from table 3 . It should be noted that CR must be lower than 0.1 to ensure the results of the comparison are acceptable. Otherwise, the judgment of the surveyed participants needs to be revised again.

Table 3. Random Consistency Index.

\begin{tabular}{lllllllllll}
\hline $\mathbf{n}$ & $\mathbf{1}$ & $\mathbf{2}$ & $\mathbf{3}$ & $\mathbf{4}$ & $\mathbf{5}$ & $\mathbf{6}$ & $\mathbf{7}$ & $\mathbf{8}$ & $\mathbf{9}$ & $\mathbf{1 0}$ \\
\hline $\mathrm{RI}$ & 0 & 0 & 0.58 & 0.9 & 1.12 & 1.24 & 1.32 & 1.14 & 1.45 & 1.49 \\
\hline
\end{tabular}

\section{Application of AHP Model}

\subsection{Decision Hierarchical Structure}

The Decision Hierarchical Structure used in the paper is shown as follow:

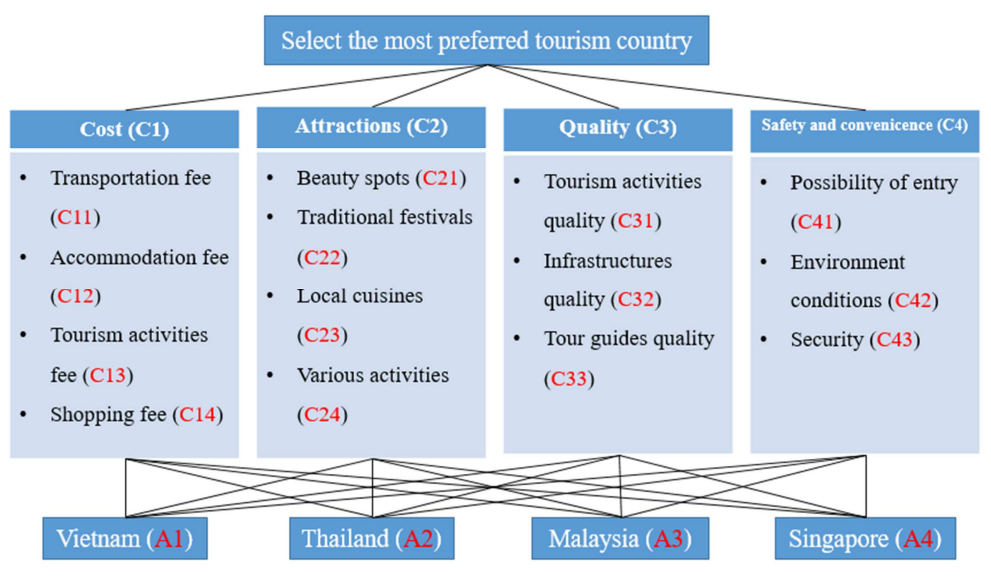

Figure 1. Decision Hierarchical Structure. 
As can be seen in figure 1 , the goal in this study is "Select the most preferred tourism country" when tourists consider choosing the destination for their vacation in Southeast Asia. In other words, the goal can be defined as the first level of the analysis. There are four criteria in the second level: Cost, Attractions, Quality, Safety and Convenience. From these criteria, one comparison matrix can be made to identify the weight of them respect to the goal. The third level consists of a total of 14 sub-criteria. Transportation fee, Accommodation fee, Tourism activities fee and Shopping fee are included in Cost. Beauty spots, Traditional festivals, Local cuisines and Various activities are formed in Attractions. Quality is assessed through three factors: Tourism activities, Infrastructure and Tour guides. The last are Possibility of entry, Environmental conditions and Security in Safety and Convenience. Four comparison matrices can be made at this level. The fourth level contains the four countries which are evaluated in term of sub-criteria in level 3. Hence, 14 comparison matrices are created for this purpose.

\subsection{Input Data}

The information survey consisting of 108 questionnaires was sent to 100 people who are working in or having experience in traveling to Southeast Asia area to determine the weight of these factors and the preferred country to travel. All participants were interviewed before taking the survey. They must be working in Asian countries or have experience in traveling there. They also have jobs with stable incomes. Most of the tourists chosen for this survey are from Korea, China, and Japan because growth across the destinations mainly came from the demand of North-East Asian source market (especially the three mentioned nation above) [15].

\subsection{Results}

In this part, the weights for all factors respects to each level and the overall composite weight of each choice based on the weight of these level are presented. Each of the comparison matrix was calculated according to the steps outlined above. The value of $\mathrm{CR}$ in each matrix was checked carefully to ensure it was in the allowable range. Table 4 shows that relating to the choice of the tourists when they want to choose a tourism destination, Quality was the most important factor at level 2. And this was followed by Cost, Safety and Convenience, Attractions respectively.

Table 4. Comparison matrix level 2 respect to the Goal.

\begin{tabular}{llllll}
\hline & C1 & C2 & C3 & C4 & Priority Vector \\
\hline $\mathrm{C} 1$ & 1 & 1.625 & 0.52 & 1.54 & 0.2489 \\
$\mathrm{C} 2$ & 0.615 & 1 & 0.49 & 0.59 & 0.1535 \\
$\mathrm{C} 3$ & 1.923 & 2.04 & 1 & 2.17 & 0.3986 \\
$\mathrm{C} 4$ & 0.649 & 1.694 & 0.46 & 1 & 0.1991 \\
$\lambda \max =4.051, \mathrm{CI}=0.017, \mathrm{CR}=0.018$ & & \\
\hline
\end{tabular}

Table 5. Overall composite weight of the 4 countries.

\begin{tabular}{llllll}
\hline & C1 & C2 & C3 & C4 & Composite weight \\
\hline Priority & 0.2489 & 0.1535 & 0.3986 & 0.1991 & \\
A1 & 0.3709 & 0.2265 & 0.0063 & 0.1411 & 0.1816 \\
A2 & 0.2932 & 0.4243 & 0.1945 & 0.1395 & 0.2434 \\
A3 & 0.2758 & 0.2404 & 0.3299 & 0.2305 & 0.2829 \\
A4 & 0.06 & 0.1 & 0.4091 & 0.4887 & 0.2919 \\
\hline
\end{tabular}

Table 6. Final ranking among four countries.

\begin{tabular}{lll}
\hline Country Name & Composite weight & Position \\
\hline Singapore & 0.2919 & 1 \\
Malaysia & 0.2829 & 2 \\
Thailand & 0.2434 & 3 \\
Vietnam & 0.1816 & 4 \\
\hline
\end{tabular}

As can be seen in table 5, Vietnam had more advantages when comparing with one another in the Cost section. Thailand led the top position in all sub-criteria which were included in Attractions criteria. Malaysia and Singapore were far superior to Thailand and Vietnam in the Quality factor. Finally, Singapore was the dominant country in the last criteria. The final ranking among the four countries is illustrated in table 6. Singapore with the highest weight was ranked the 1st and followed by Malaysia. Thailand and Vietnam took the 3rd and 4th place respectively.

\section{Comparative Analysis}

\subsection{Summary of AHP Model Results}

From the results calculated by the AHP method, the advantages and disadvantages of each country are summarized in table 7. These features which based on experiences of the surveyed tourists reflect their opinion for each country they had been to. In the table, all the advantages and disadvantages are built on results from 14 comparison matrices at level 4. This result is a valuable contribution to the authority organization in improving and developing the marine tourism industry of the four countries.

Table 7. Advantages and disadvantages of each country.

\begin{tabular}{lll}
\hline & Advantages & Disadvantages \\
\hline \multirow{4}{*}{ Vietnam } & Cost & Infrastructures quality \\
& Beauty spots & Activities quality \\
& Local cuisines & Tour guides quality \\
& Security & Environmental conditions \\
& Cost & Possibility of entry \\
Thailand & Beauty spots & \\
& Local cuisines & Environmental conditions \\
& Traditional festivals & Security \\
& Various activities & \\
& Cost & \\
& Beauty spots & \\
& Local cuisines & \\
Traditional festivals & Environmental conditions \\
& Various activities & \\
& Infrastructure quality & \\
& Tour guides quality & \\
\hline
\end{tabular}




\begin{tabular}{lll}
\hline & Advantages & Disadvantages \\
\hline \multirow{4}{*}{ Singapore } & Infrastructure quality & \\
& Tour guides quality & Cost \\
& Activities quality & Beauty spots \\
& Environment conditions & Traditional festivals \\
& Possibility of entry & \\
Security & \\
\hline
\end{tabular}

\subsection{Comparative Analysis}

Table 8. Travel \& Tourism Competitiveness Index (best score: 7).

\begin{tabular}{lllll}
\hline & Vietnam & Thailand & Malaysia & Singapore \\
\hline Price & 5.3 & 5.6 & 6.1 & 4.7 \\
$\begin{array}{l}\text { Competitiveness } \\
\text { Environmental }\end{array}$ & 3.4 & 3.6 & 3.5 & 4.3 \\
$\begin{array}{l}\text { Sustainability } \\
\text { Infrastructures }\end{array}$ & 2.8 & 3.8 & 4.6 & 5.6 \\
$\begin{array}{l}\text { Natural } \\
\text { Resources }\end{array}$ & 4.0 & 4.9 & 4.1 & 2.4 \\
$\begin{array}{l}\text { International } \\
\text { Openness }\end{array}$ & 3.0 & 3.8 & 4.1 & 5.2 \\
$\begin{array}{l}\text { Safety and } \\
\text { Security }\end{array}$ & 5.6 & 4.0 & 5.8 & 6.5 \\
\hline
\end{tabular}

Table 8 shows the Travel and Tourism competitiveness index [1] of the four countries in 2017. This index was performed by the World Tourism Organization (UNWTO) and the World Travel and Tourism Council (WTTC). The tourism performances of the four countries were evaluated by many criteria. Among them, Price Competitiveness, Environment Sustainability, Safety and Security, Natural Resources, International Openness, and Infrastructures were the main criteria used in this comparative analysis because of their similar meanings with the criteria used in the AHP model. The score of each country corresponded to each factor was from 1 to 7 .

It is clear from the table that Singapore was always leading in most comparison criteria except for price competitiveness and natural resources. However, Singapore's natural resources shortage is offset by modern infrastructures, advanced technology, international openness, good security situation, and environment. There were not so many differences between Malaysia, Thailand and Vietnam in the environment and natural resources comparison. Malaysia's strong points are from price competitiveness, quality infrastructures, and safety. Thailand had advantages in price and natural resources but the country also had negative effects due to unstable safety and security. In 2017, although Vietnam was the most improved country in Southeast Asia, there were many weaknesses in the country tourism industry such as limited infrastructures and international openness, unsustainable environment and tourism activities quality. If these weaknesses can be improved in the future, combining with the current strengths such as price, natural resources, and safety, the country's tourism industry can achieve better results in the following years.

As the comparative analysis results show, there are no significant differences between the findings from the AHP method and the index analyzed by UNWTO and WTTC. Most of the comparative criteria showed the consistent advantages and disadvantages of each country. The only difference between the results relates to the Cost criteria. While Vietnam was chosen as a country with a cost advantage by the surveyed participants, Malaysia was identified as a country that has better price competitiveness by the mentioned organizations. However, this difference is negligible.

\section{Conclusions}

This study has investigated the current status of the tourism industries of the four countries (Vietnam, Thailand, Singapore, and Malaysia) which are currently in a fierce competition in Southeast Asia by using the AHP method. The input data for this AHP model was from a questionnaire survey with 100 participants who are working in Southeast Asia or having experiences in traveling there. The findings show that Singapore has been the most preferred tourism country, followed by Malaysia, Thailand, and Vietnam, respectively. According to the results, quality is the most important factor to be concerned when the tourists consider traveling to the area.

Besides, a comparative analysis between the findings from this research and the statistics from UNTWO and WTTC was also carried out. The analysis outcomes confirm the accuracy as well as the reliability of the AHP model employed in this study. The research suggested the pros and cons of each country in attracting tourists, which act as reference sources for travelers who plan to visit the Southeast Asian countries. More to the point, the authority in charge of tourism of the four countries can get access to the research results to promulgate relevant policies to improve the competitiveness of their tourism industry.

The weakness of this research is a small size and undiversified sample of participants who took part in the questionnaire survey. Further research shall consider the ideas from experts in this field as well as tourists from other parts of the world.

\section{References}

[1] World Economic Forum, "The Travel and Tourism Competitiveness Report 2017".

[2] World Travel \& Tourism Council, "Travel \& Tourism Economic Impact 2018 (Vietnam, Thailand, Singapore, Malaysia)".

[3] World Travel \& Tourism Council, "Travel \& Tourism Economic Impact 2017 (Vietnam, Thailand, Singapore, Malaysia)".

[4] Murphy, Laurie (1999), "Australia's image as a holiday destination - perception of backpacker visitors", Journal of Travel and Tourism Marketing, Vol. 8.

[5] Lai, Lai-hsin, Graefe, Alan R. (2000), "Identifying market potential and destination choice factors of Taiwanese overseas travelers", Journal of Hospitality and Leisure Marketing, Vol. 6. 
[6] Kaushik N., Kaushik J., Sharna P. and Rani S. (2010), "Factors Influencing Choice of Tourist Destinations: A Study of North India", Journal of Brand Management, Vol. 7.

[7] Nekooee Z., Karami M., and Fakhari I. (2011), “Assessment and Prioritization of Urban Tourist Attractions Based on Analytical Hierarchy Process (AHP): A Case Study of Birjand, Iran", Iran Journal of Applied Business and Economics, Vol. 12.

[8] Cetinsoz B., Artuger S. (2014), “International Tourists' Selection Criteria for Choosing All-Inclusive Package Tours: An Application in Istanbul", International Journal of Academic Research in Business and Social Sciences, Vol. 4, No. 9.

[9] Seyidov J., Adomaitiene R. (2016), "Factors Influencing Local Tourists' Decision-Making on Choosing a Destination: A Case of Azerbaijan", Ekonomika, Vol. 95.

[10] Angelos Pantouvakis and Chritos Patsiouras (2016), "Tourists' Selection Criteria and Motivation. Does Nationality Matter?", SPOUDAI Journal of Economics and Business, Vol. 66.
[11] Kirti Singh Dahiya and Dharminder Kumar Batra (2016), "Tourist decision making: Exploring the destination choice criteria", Asian Journal of Management Research, Vol. 7.

[12] Debski M., Nasierowski W. (2017), "Criteria for the Selection of Tourism Destinations by Students from Different Countries", Foundations of Management, Vol. 9.

[13] Luan Chen, Eric Ng, Shyh-Chang Huang and Wei-Ta Fang (2017), “A Self-Evaluation System of Quality Planning for Tourist Attractions in Taiwan: An Integrated AHP-Delphi Approach from Career Professionals", Journal of Sustainable Tourism, Vol. 9.

[14] R. W. Saaty, 1987, The Analytic Hierarchy Process - What It is and How It is Used, Mathematical Modelling, Vol. 9, No. 3-5, pp. 161-176.

[15] UNWTO, “UNWTO Tourism Highlights”, 2018 Edition. 